\title{
Collaboration, competition and innovation: a consortium of tribology in the automotive sector
}

\author{
Ana Paula Lopes ${ }^{\mathrm{a}, \mathrm{b} *}$ (D), André Ferrarese ${ }^{\mathrm{a}}$ (D), Marly Monteiro de Carvalho \\ aUniversidade de São Paulo, São Paulo, SP, Brasil \\ ${ }^{\mathrm{b} C e n t r o ~ U n i v e r s i t a ́ r i o ~ F E l, ~ S a ̃ o ~ B e r n a r d o ~ d o ~ C a m p o, ~ S P, ~ B r a s i l ~}$ \\ *paulavlopes@outlook.com
}

\begin{abstract}
Paper aims: The collaboration among competitors represents a substantial challenge for most innovation processes of companies. This research aims to explore the factors influencing collaboration for innovation that involves competitors in the Fuzzy Front End phase.

Originality: This study provides an important advance in three aspects. First, it brings outstanding contributions to the process of generation of ideas and knowledge in a context that involves collaboration and competition simultaneously. In addition, the research examines how this has evolved over time, which were the main difficulties, which were the most significant barriers and necessary efforts to mitigate them. Another important contribution was learning generated on how to work ideas and opportunities in the Fuzzy Front End phase of innovation. Finally, it contributes to the identification of the main roles of Universities in this context.
\end{abstract}

Research method: The findings from a detailed case study on a Brazilian University-industry consortium in the automotive sector are presented.

Main findings: The results indicate a concentration of companies in three main groups with very different operations: the group related to the ring and cylinder lubrificantion system, the automakers and Universities.

Implications for theory and practice: The main practical and theoretical contributions of this research is exactly the pioneering nature with regard to automakers working collaboratively.

Keywords

Innovation management. Competition. Collaborative work.

How to cite this article: Lopes, A. P., Ferrarese, A., \& Carvalho, M. M. (2019). Collaboration, competition and innovation: a consortium of tribology in the automotive sector. Production, 29, e20180106. https://doi.org/10.1590/0103-6513.20180106

Received: Dec. 12, 2018; Accepted: Mar. 20, 2019.

\section{Introduction}

Gain competitive advantage in an environment of rapid changes and in face of the need for increasingly innovative products, in time cycles increasingly shorter has proven a major challenge for companies (Bidault \& Castello, 2009; Lin et al., 2014; Popa et al., 2017). It is more common in the literature to find research papers that relate cooperation in research and development to product innovation, since companies have access to external knowledge, using it to obtain more innovative products (Un \& Asakawa, 2015).

However, research indicates more and more the importance of companies to engage in the Fuzzy Front End phase of innovation, which is the earliest and most widespread part that refers to the stages of generation and selection of ideas and opportunities (Frishammar et al., 2015; Zhao et al., 2017). The Fuzzy Front End phase can be considered one of the most difficult and important stages of the innovation process, both because of its direct impact on the success of new products and due to opportunities for improvement offered. In this 
research, this perspective is very present in the perception of the environment preparation for promoting new product concepts.

One of the main factors that lead companies to seek collaboration is the joint development of knowledge, considering costs, complexity, uncertainties and risks involved in the innovation process (Chang, 2003; Lin, 2017; Ritala et al., 2015). When the collaboration involves Universities, some specificities and challenges arise such as different organizational cultures and different ways of management (Bstieler et al., 2015).

In a complex environment of innovation, there is some consensus on the need to seek external complementarities in the innovation process (Bogers, 2011; Cheng \& Huizingh, 2014; Christensen, 1997; Huston \& Sakkab, 2007; Nooteboom, 1994; Perkmann \& Schildt, 2015; West \& Bogers, 2014), promoting integration between internal and external competences (Buganza \& Verganti, 2009), and better innovation results (Un \& Asakawa, 2015; Caloghirou et al., 2004; Cammarano et al., 2017; Chang, 2003; Faems et al., 2005; Garcia \& Calantone, 2002; Greco et al., 2017; Kafouros et al., 2015; Lau \& Lo, 2015; Nieto \& Santamaría, 2007; Ritala et al., 2015; Schilling \& Phelps, 2007).

However, there are few studies that allow collaboration to be understood with multiple players, particularly involving competitors. The objective of this research is to explore the factors that influence the phase Fuzzy Front End of innovation in a collaborative competitive environment. This paper fills a research gap by examining the following questions: RQ1: which factors influence the collaboration for innovation in environments that involve competitors? RQ2: how the collaboration dynamics can affect the generation of innovation?

To investigate these questions a longitudinal case study was conducted in a consortium in the Brazilian automotive sector consisting of Universities, automakers, suppliers of 1st and 2nd tiers, and complementors in the oil and gas sector. The consortium refers to the Fuzzy Front End phase to develop new skills and concepts related to the area of tribology. This theme is particularly important in the context, mainly for the development of cars powered by ethanol, which required an intense engineering work until the advent of flex fuel technology, which allows cars to be fueled with gasoline, ethanol, or any mixture of the two.

This paper is structured as follows. The second section presents the theoretical substantiation of the research. In the third section, the empirical study is detailed. In After the results are presented, analyzed and discussed. The last section ends the research with the conclusions, limitations and indications of future research.

\section{Literature review}

\subsection{Innovation}

Innovation is defined in the literature as: "[...] an introduction of a new product, a novel method of production, opening new markets, the use of new sources of supply, and new forms of competition that lead to the restructuring of an industry" (Schumpeter, 1934, p. 32); "A new or better product or production process successfully commercialized" (Pavitt, 1984, p. 344); "The initial market introduction of a new product or process whose design departs radically from past practice" (Abernathy \& Clark, 1985, p. 6); "Certain technical knowledge about how to do things better than the existing state of the art" (Teece, 1986, p 288);

An interactive process initiated by the perception of a new market and/or new service opportunity for a technology based innovation which leads to development, production, and marketing tasks striving for the commercial success of the innovation invention (Garcia \& Calantone, 2002, p. 112).

For this research a synthesis was developed, which defines and considers innovation as an interactive process of generation, dissemination and application of knowledge, which results in the implementation of a new product (good or service) or significantly improved, or a new production method, or a new marketing method, or a new organizational method in order to obtain the commercial success of the invention.

The term Fuzzy Front End was adopted in the innovation literature because these activities are often diffuse and poorly structured in organizations, compared to the product development stages (Kim \& Wilemon, 2002; Koen et al., 2001; Takey \& Carvalho, 2016). This is the early stage of the innovation process. The company should seek a holistic view of the process, remaining aligned internally, but also monitoring changes in the environment with respect to the market for new customer demands and movements of competitors (Carvalho, 2009). At this stage, important decisions about the target market characteristics, value propositions, cost and products are taken. All these decisions are then made based on the product concept and design, which serves to guide development activities (Smith \& Reinertsen, 1998). The Fuzzy Front End phase is characterized by the uncertainty of the information used, dynamic scenarios, and low levels of formalization (Murphy \& Kumar, 1997). So it is at this stage that the organization strategy is divided into project proposals that will facilitate strategic planning. It is also at this stage that prospecting is done and that experts in key areas for the organization are accessed. 


\subsection{Collaboration}

Previous research has pointed to collaboration as a means of mitigating the pressure to reduce costs and time in the new product development process (Amara \& Landry, 2005; Morrison et al., 2000; Nieto \& Santamaría, 2007). In this context, collaboration based on an interactive process among players becomes necessary (Edwards, 2000), which extend from technology transfer agreements, agreements with Universities for the development or joint exploitation of a patent for joint development of products (Chang, 2003; Faems et al., 2005; Santoro \& Saparito, 2003).

The main advantages that can be obtained in $R \& D$ collaboration are "[...] the cartelization factor, the spillover factor, the complementarity factor, the subsidization factor, and the national commitment factor. On the other hand" (Odagiri et al., 1997, p. 203). On the other hand, there are disadvantages like "[...] the incentive for free-riding, the conflict of corporate culture, and the possibility of anti-competitive consequences" (Odagiri et al., 1997, p. 203).

Relationships between Universities and companies have grown significantly in recent years (Bruneel et al., 2010; Bstieler et al., 2015; Huang \& Chen, 2017; Sherwood \& Covin, 2008; Tether \& Tajar, 2008). Universities play an important role in the collaboration with companies, particularly with respect to process and product innovation (Un \& Asakawa, 2015). It is important that companies that work in collaboration with universities have conscience of how to work internally the knowledge generated in the university (Armellini et al., 2011).

There are many types of connections that can occur between companies and Universities: research partnerships, research services, academic entrepreneurship, transfer of human resources, interactions, information, marketing of property rights, scientific publications (Perkmann \& Walsh, 2007). The generated learning was also the focus of prior studies (Ariño, 2003; Gulati \& Singh, 1998; Harrigan \& Newman, 1990; Kogut, 1988). According to Branstetter \& Sakakibara (2002), the performance of a consortium involving companies and universities is greater when it involves basic research. In the environment of the automotive industry, relationships with focus on technological development are quite common, and their goal is to explore the concepts of engine technologies, yet to be implemented.

The rights to the intellectual property of innovations arising from the collaboration between companies and Universities represent a major barrier in this type of relationship (Bstieler et al., 2015).

\subsection{Knowledge creation}

One of the main objectives of companies seeking to innovate through collaboration is the generation of knowledge (Caloghirou et al., 2004; Cheng \& Shiu, 2015; Ghisetti et al., 2015; Ritala et al., 2015). Research and development partnerships favor the obtaining of learning and knowledge, and the development of important skills for the internal process of innovation (Bidault \& Castello, 2009; Ingham \& Mothe, 1998; Kim et al., 2016; Sherwood \& Covin, 2008).

In this process of search for knowledge it is important to consider the following concepts: the concept of absorptive capacity, which refers to the ability of companies to assimilate external knowledge and skills, applying them and converting them into value and marketable final goods (Cohen \& Levinthal, 1990; Naqshbandi, 2016) and concept of dynamic capabilities, which relates to the ability of a company to integrate, build and reconfigure internal and external expertise in order to obtain profits from its innovation (Teece et al., 1997).

The generation of knowledge passes through the generation process of idea obtained externally, which needs to be properly worked internally (Kessler et al., 2000; Mangematin \& Nesta, 1999). In this sense, some companies face a phenomenon known as $\mathrm{NIH}$ - Not Invented Here, i.e., there is an internal resistance to work ideas generated externally (Gesing et al., 2015; West \& Bogers, 2014).

Ritala et al. (2015) showed the term "knowledge leakage" which refers to knowledge that is poorly managed by the company. The authors analyze that while the exchange of knowledge is something expected by employees in a collaborative relationship, "[...] knowledge leakage is unwanted (accidental or intentional) behavior by employees who share knowledge that the firm would rather book internally” (Ritala et al., 2015, p. 24).

\subsection{Coopetition}

Coopetition is a relationship in which partners collaborate and compete at the same time (Brandenburger \& Nalebuff, 1995; Gnyawali et al., 2006; Gnyawali \& Park, 2009, 2011). Research indicates that the ideal balance between collaboration and competition favors the obtainment of knowledge and the ability of companies to obtain better results in innovation (Erez et al., 2016; Jorde \& Teece, 1989; Quintana-García \& Benavides-Velasco, 2004). 
One of the main factors that leads companies to adopt a coopetition strategy is to fill a gap of capabilities internally, which often would represent a high cost for the company to develop, and that partners have (Gnyawali \& Park, 2009; Shvindina, 2017). Also according to these authors, coopetition can promote benefits such as economies of scale; reduction of risks and uncertainties, and decreased product development time.

The interaction logic in this type of relationship is different, since conflicts of interest go hand in hand with the need to build a relationship of trust with mutual commitments (Quintana-García \& Benavides-Velasco, 2004).

The position of each actor in the coopetition net can make the difference in the results of each one of them (Gnyawali et al., 2006). The results of this research indicate mainly that the players more central offices can be more benefited, in relation to the attainment of information, what it can favor the attainment of competitive advantage directly.

Coopetition relationships involving large competing companies have high levels of stress, and a major risk that these companies have is the partner of misappropriation (Gnyawali \& Park, 2011).

\section{Research method}

This research seeks to answer the following questions: RQ1: which factors influence the collaboration for innovation in environments that involve competitors? RQ2: how the collaboration dynamics can affect the generation of innovation?

The research method chosen was the longitudinal case study. The chosen case was a consortium focusing on research on tribology and mechanical impacts of flex fuel technology in internal combustion engines. The choice of this case was intentional, since it was a pioneering consortium in Brazil, which involves competing automotive companies working in collaboration with each other and with other companies and Universities. A key differentiator of the choice of this case was the chance to analyze the consortium since its proposal in 2009 until its closure in 2016.

\subsection{Data collection}

Data collection was done through analysis of documents, direct observation of researchers and semi structured interviews (Eisenhardt \& Graebner, 2007). The document analysis involved checking the minutes and attendance lists of meetings held; material of presentations made at meetings; material of annual reports of the consortium accounting; content of the consortium articles published in scientific journals and conferences; material of dissertations and theses completed during the consortium; materials of the courses offered.

Another aspect that allowed a deep knowledge of the case was the access to the material of the entire website created for the consortium. Login and password were made available to researchers. Direct observation was through the participation of researchers in meetings of the consortium over the five years of duration, as well as several informal conversations about the consortium with direct interlocutors in companies and Universities. Throughout the consortium lifecycle there was continuous expansion and improvement of the research protocol as suggested by the literature. Recording of meetings and workshops was not allowed, but it was allowed to take notes and have access to the minutes later. After conversations with team members (informal interviews) relevant topics identified were included, which were not addressed in the protocol.

In the final period of analysis, it was chosen to use semi-structured interviews with key persons of the consortium, who stood out over the five years (see Appendix A). For the interviews a research protocol was developed. Each consortium organization had the presence of an employee more directly involved in the project. It was chosen to conduct the interviews with these people in order to talk to people not only more familiar with the consortium but with more background information as well. Seven interviews were conducted that followed the research protocol developed (See Table 1). In addition to these interviews, the various aforementioned

Table 1 . List of interviewees.

\begin{tabular}{lccc}
\hline \multicolumn{1}{c}{ Group } & Company code & Position of the interviewee & Intervieres code \\
\hline & Org_1A & R\&D Technical Consultant & Int_1A1 \\
& Org_1A & Head of Innovation Management & Int_1A2 \\
1- Suppliers & Org_1B & Processing Engineer & Int_1B1 \\
& Org_1B & Innovation consultant & Int_1C1 \\
& Org_1C & Researcher & lnt_2A1 \\
2 - Car builder & Org_2A & Design Engineer & lnt_3A1 \\
$3-$ Universities and Institute of Technology & Org_3A & Professor & \\
\hline
\end{tabular}


informal talks were very important for the development of the research protocol, and for clarifications of the consortium planning and execution.

\subsection{Data analysis}

Regarding the document analysis all the material obtained directly from the consortium website was dealt with systematically. After downloading the website files, the material was organized by type: minutes, attendance lists, presentations, annual reports for accounting, publications (articles, dissertations and theses), and course materials.

Regarding the interviews of the final phase, all were recorded, transcribed and content sent to interviewees for analysis and confirmation of accuracy of the information. After we made the necessary adjustments in the transcripts of the interviews, their content, and all the material of document analysis were coded. One of the great challenges of qualitative research as a case study is the analysis of a large amount of data. The coding was made according to the open coding technique (Corbin \& Strauss, 1990; Locke, 2003; Strauss \& Corbin, 1990). Codes were created in line with the main constructs of the literature (See Table 2). For each indicator one question was elaborated at the research protocol. The categories $\mathrm{B}, \mathrm{C}$ and $\mathrm{F}$ allowed us to answer the first research question: which factors influence the collaboration for innovation in environments that involve competitors? Already the categories A, D and E allowed us to answer the second research question: how the collaboration dynamics can affect the generation of innovation?

Table 2. Categories and analysis indicators.

\begin{tabular}{ll}
\hline \multicolumn{1}{c}{ Category } & \multicolumn{1}{c}{ Indicator } \\
\hline Category A - Collaboration & A1 - Area responsible for the consortium \\
& A2 - Business unit \\
& A3 - Intellectual property \\
& A4 - Partners kinds \\
& A5 - Strategic importance of each partner \\
& A6 - Selection of partners \\
& A7 - Motivating factors partnerships \\
& A8 - Interaction between partners \\
& B1 - Coopetition \\
Category B - Knowledge & B2 - Number of partners \\
& B3 - Knowledge management \\
& B4 - Absorptive capacity \\
& B5 - Similarity technology \\
Category C - Trust & B6 - Geographical proximity \\
Category D - Communication and project documentation & C1 - Trust \\
& D1 - Types of meetings \\
& D2 - Contract preparation \\
& D3 - Dissemination of information \\
Category E - Innovation & D4 - Leadership in the consortium \\
Category F - Performance & E1 - Generating ideas \\
& E2 - Relationship between engine technology and innovation \\
& F1 - lnnovation performance \\
& F2 - Consortium Performance \\
\hline
\end{tabular}

\section{Presentation, analysis and discussion of results}

For reasons of confidentiality, the names of the respective companies and Universities that make up the consortium will not be shown. For the presentation and analysis of results codes of each company will be used. Three main groups of companies were created according to the operation of each in the consortium, namely: group 1 (suppliers), group 2 (automakers), and group 3 (Universities and Institute of Technology). The results will be presented, analyzed and discussed considering these groups. In addition to the three groups of companies that make up the consortium, there was also participation in the meetings of invited companies, which will be analyzed separately. These companies made some presentations and attended courses or lectures. 
For description of the network of this consortium, it is important to understand the role of players and coopetition stresses among them, as illustrated in Figure 1. The arrows represent the knowledge flow of the collaboration network.

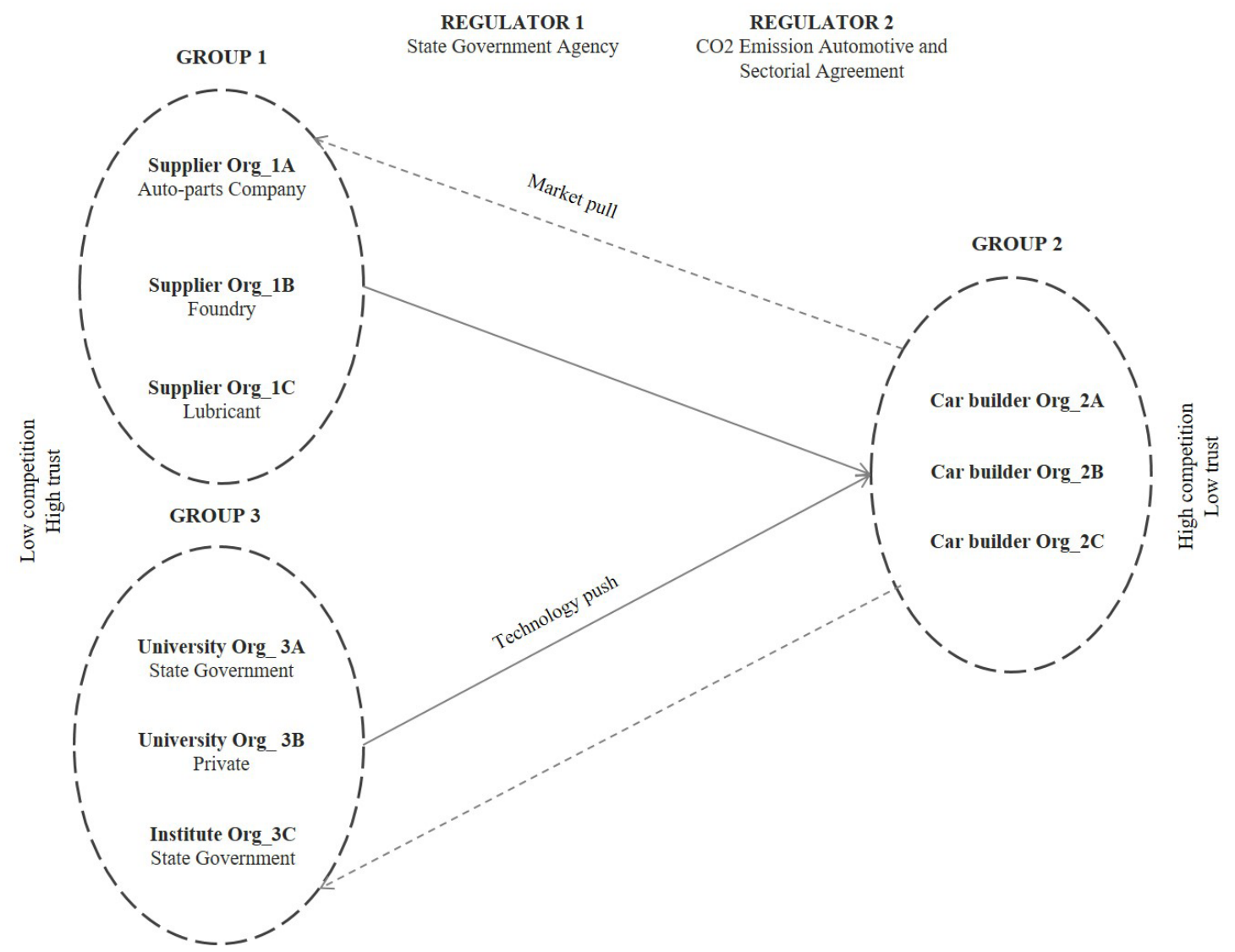

Figure 1. Network of collaboration involving companies and universities.

It is observed that in the proposal phase the project was pushed by groups 1 and 3, which had the sharpest skills in Tribology (technology push), and would like to empower them through the consortium. It is also worth noting that at the beginning the project was pushed by business ecosystem elements that did not compete with each other, but in fact were complementary in their competences. It was the motivation and empowerment of the companies in groups 1 and 2 that enabled the project with Brazilian development entities, and obtained the financial contribution of the companies of the three groups.

As a whole, 39 meetings took place, involving participants of the 3 car builders, 3 suppliers and 3 universities / institute of technology. These meetings encompassed three distinct types of meetings; technical meetings, steering committee meetings, and courses. There was a greater participation of firms of companies in group 3, which are Universities and Institute of Technology. This is because Universities involve a large number of students and professors.

It was observed a strong relation between the level of participation and the result in terms of publications, when stratified by group. As a whole, 27 publications were generated; 1 doctoral thesis, 4 master's dissertations, 9 articles published in conferences and 13 articles published in journals.

There were 56 presentations during meetings of the consortium, which was related to one of the consortium programs. These presentations dealt mainly with matters relating to the planning and progress of the consortium, considering the contractual part, decisions to be taken, evolution of publications, dissertations and theses, as well as more technical aspects such as, for example, topics to be studied (materials, technologies) equipment to be purchased, tests to be performed. Throughout the consortium, eleven devices were purchased. 


\subsection{Collaboration}

Regarding the area responsible for projects, companies allocated the consortium mainly to the areas of innovation, research, or research and development (indicator A1). Neither company has a specific department of open innovation, but they all work long through collaboration. There was disagreement among companies as to the involvement of other business units (indicator A2). In Universities there was an involvement mainly of the department of mechanical engineering, and in companies of the departments of research and engine components.

Intellectual property was a subject much discussed in the consortium preparation phase (indicator A3). The intellectual property agreement took a year to be signed due to the demands of the legal department of companies. The consortium business ecosystem greatly influenced this stage. The high degree of competition and low degree of trust among companies in group 2 hindered and delayed the project progress. With the consortium evolution participants concluded that for being a pre-competitive consortium, there would not be intellectual property and this greatly facilitated the work.

It is possible to see in Figure 1 how the type of partner influenced the formation and evolution of the consortium (indicator A4). It is clear from the interviews that companies distinguished the division of participants into the three groups described in this research. Group 1 contains the skills related to the engine block, components of the engine block and lubricants. Group 2 represents the environment, and group 3 is mainly responsible for qualification of people involved, as well as for the generation and distribution of knowledge, as per interviewee lnt_3A1:

[...] We have examples of people who work with engine tribology in several companies that have developed qualification individually or by demand of the company. Now, doing it in a structured way was an idea that came and was mature throughout the consortium.

The presence of Universities certainly favored the group learning (Ariño, 2003; Gulati et al., 2000; Harrigan \& Newman, 1990).

More important than determining a strategic role for each participant was to understand how each one could contribute to achieving the ultimate goal (A5 indicator), as per interviewee lnt_1B1:

[...] We need to understand the movement of industry. Understand where it's going, where it is expected it to go and what each has to offer.

The selection of partners was also greatly caused by business ecosystem of the consortium and personal relationships (indicator A6). Members of company Org_1A knew a professor at University Org_3A that together started the project outline. The other companies and Universities were also invited by acquaintances, as per interviewee lnt_1A2:

[...] For the consortium, personal relationships are very important. We invite people we know.

Regarding the factors that caused companies to enter the consortium, group 1 highlighted the importance of getting closer to automakers in order to get involved earlier and earlier in the planning of engines, parts and engine lubricants (indicator A7). This group aimed an approach to understand in advance the needs of automakers. Improve to meet the requirements of the laws was also a motivating factor, especially for companies in group 2.

Generation of knowledge and sharing of costs and risks of research were also important motivating factors, as already pointed out by previous research (Amara \& Landry, 2005; Morrison et al., 2000; Nieto \& Santamaría, 2007). The interaction among companies has changed a lot over the five years. Some companies even began to work on projects in parallel to the consortium (indicator A8).

\subsection{Knowledge}

When asked about the flow of knowledge in the consortium, considering the existence of competitors, companies agreed that there was a good flow of work between companies in groups 1 and 3, as shown in Figure 1 (indicator B1). For being the first time that companies in group 2 work collaboratively with each other and with others, this reinforces the low experience in this mode of work, as per interviewee lnt_1A1:

[...] I see the flow of knowledge between automakers and other companies quite limited. I believe that the universe of sharing is somewhat typical in Brazil. The consortium is helping these companies in the learning process of collaboration. 
Although coopetition showed to be an important barrier in the flow of knowledge between automakers and other companies, it was not a major barrier to the achievement of the consortium goals. It was a learning process and it was possible to realize that negative impacts of coopetition were mitigated throughout the consortium, mainly by positive interpersonal relationships among stakeholders.

The results indicate that there was an adequate number of firms and individuals by companies in the consortium (indicator B2). For being a pioneer project it required learning, since the greater the number of persons, the greater the challenge, as per interviewee lnt_1A1:

\section{[...] Part of learning with the group was managing expectations of different players, and they would work differently.}

All companies pointed out the importance of personal relationship to the generation and management of knowledge (B3 indicator). No matter how much the consortium generated information and therefore knowledge, the results indicated a deficiency by companies in how to disclose and use this knowledge internally, as per interviewee lnt_1A2:

[...] The critical point is how to spread knowledge generated in the consortium. The great difficulty we have is how to transfer or how to generate value from this knowledge.

Companies did not have a clear idea of how it would be to manage a complex project. A website was created to store all the consortium information. How each company made the management of knowledge generated internally diverged enough. Some companies concentrated information in people responsible for the consortium. These people analyzed the content and checked how they could disseminate this knowledge, creating value for the company. Others did it in a more structured way, performing internal meetings to share knowledge generated and analyze how it could be used.

The group emphasized the importance of a more qualitative analysis and distribution of all knowledge generated in the consortium. Many people and even other projects inside companies could have been benefited from knowledge generated in the consortium, if such knowledge had been better disclosed, which is configured as "Knowledge leakage" (Ritala et al., 2015).

Awareness that there is a direct relationship between good use of knowledge generated in partnership and gaining competitive advantage is noticed by interviewees. However, this process requires attention, as per interviewee lnt_1A1:

[...] This transformation is not so straightforward. This requires a much more long-term view to be able to see the benefit in the chain.

The absorptive capacity of companies was evaluated in this consortium by the number of publications (indicator B4). Group 3 was able to mobilize a significant number of professors and students, which reflected the number of publications. The fact that mechanical tests have been conducted in Universities also favored the participation of group 1 in the results of publications. The collaboration network of the consortium shows that it does not a direct relationship between the companies of groups 1 and 3. This relationship was intermediated by the companies of group 2. The companies of group 2 were essential to transform the technical information of the group 1 in a more academic language for the group 3.

Companies do not believe that having technological similarity among partners is a requirement for a good evolution of the consortium (indicator B5). However, the geographical similarity was important in the consortium, considering that two of the companies are from a different state with respect to the others (indicator B6).

This fact did not limit the operations of these companies in the consortium, but a greater presence at the meetings. To minimize this impact, the consortium included the use of resources such as Skype and Webex (software for voice communication and image sharing). Webex was made available at all meetings.

\subsection{Trust}

Within the consortium, trust mainly favored the sharing of information necessary for the project progress (Bidault \& Castello, 2009; Blomqvist et al., 2005) (C1 indicator). Despite initial barriers caused by low confidence among companies in group 2, an example of an effort of these companies was the sharing of tribology system parts for analysis and tests.

Another benefit arising from trust was the creation of projects in parallel to the consortium, involving some companies and Universities. Companies are aware that they need to be careful in these new projects in parallel. What they know and have information from a company in the consortium may not necessarily be shared with 
the new project group. The dialogue among companies was essential in establishing trust, especially in group 2 (Jameson et al., 2006).

Companies reported that for having Universities involved in the consortium the development of trust among partners was facilitated (Bruneel et al., 2010). University 1, which had a more intense participation in the consortium, acted greatly as a mediator, as per interviewee lnt_1C1:

[...] lt's almost an indirect trust. Companies entrust information to the University, which adequately disclose it without breaking the technological secrecy companies.

\subsection{Communication and project documentation}

Companies basically gathered during the consortium formal meetings (D1 indicator). There were also telephone contact and through email. The consortium agreement was a major challenge. Besides being a pioneering project for companies, it was for the public institution of development as well. It had an agreement model that involved several companies and one University, but did not have an agreement model involving several companies and several Universities. This was one of the reasons that contributed to the delay in the agreement proceduring. The agreement also proved to be a challenge internally in companies, as per interviewee lnt_2A1:

[...] At first people did not see the benefits that the consortium could offer. They focused greatly on the competition side, which hindered the agreement signature.

All the information disclosed on the consortium website was also sent by email to the consortium participants (D3 indicator). This disclosure concentrated on one person of company Org_3A. The results indicate that companies greatly regretted the lack of planning of the consortium considering a person to work in the organization of the material, sending of information, and site administration. Disclosure happened, but far short of what could have been done, as per interviewee Int_3A1:

[...] 1 think this is the point where the consortium left more to be desired. 1 would not work in another consortium of this size without a person to perform this role.

There was no formal manager in the consortium, but some people were instrumental in the consortium preparation and execution (D4 indicator). Some strongly contributed to know both the academy and company sides. Master's, doctorate and postdoctoral students/scholars contributed a lot with their research. Others contributed in a special way during the project preparation phase to be sent to the public institution of development. There was also strong contribution of some people in the legal proceduring of the agreement. It became very evident that the group felt the lack of a formal manager, as per interviewee lnt_1C1:

[...] The figure of a consortium manager is something that will definitely be on the guidelines of a description of an upcoming consortium of this type. It is something that is fundamental to the different needs and formalization of knowledge.

\subsection{Innovation}

The consortium did not have a structured process of idea generation (E1 indicator). Companies ended up being greatly based on how they work the generation of ideas internally. The process blended spontaneous ideas with the analysis of opportunities and meeting of needs. The generation of ideas in the consortium did not focus on developing new products. Companies were more concerned in understanding the state of the art.

Innovation in the automotive sector is very motivated by the regulators of Figure 1, which require more efficient engines with lower fuel consumption and lower CO2 emissions. The legislation ends up being a technology lever (E2 indicator), as per interviewee Int_1A2:

\section{[...] Not only in Brazil but worldwide, engine are innovations linked to emission regulations.}

Innovation in the automotive sector is also motivated by the peculiarity of ethanol in Brazil, as per interviewee Int_1C1:

[...] We have alcohol; therefore, we are forced to innovate in this direction. The problem is always connected to weight decrease and friction reduction to make the most efficient engine possible, to consume less fuel, to pollute less. 


\subsection{Performance}

The main indicators used to measure innovation performance are: number of patents, number of products launched, number of academic publications and number of ideas, always considering a scenario of the last three years (F1 indicator). In this context the consortium, despite not having reached the product development stage, had good innovation results considering the number of scientific publications and the number of ideas generated (Un \& Asakawa, 2015; Kafouros et al., 2015).

Regarding the consortium performance itself, an important assessment milestone is the accounting report of the public institution of development (F2 indicator). In this report most important information of the consortium advance is reported. All materials related to meetings, sub-projects, publications, courses, etc. are attached to the reports.

In these reports companies make an assessment of the project progress, as per interviewee lnt_2A1:

[...] So far, the Consortium is adding value to our company in the following points: courses offered within the consortium are being passed on inside the company through technical discussions or even as mini courses on the topic generating sharing of acquired knowledge; a group dedicated to tribology was created internally in order to enhance and disseminate the discussions and technical papers that are generated within the consortium, aiming the search for technical solutions for our products or even gain of internal know-how of the group.

And interviewee lnt_1A2:

[...] The innovative initiative of a precompetitive project like this involves in particular the difficulty of internalization of knowledge by companies. Thus, the project development has improved markedly different instruments that help in that direction. High quality courses promoted by the project have involved different stakeholders of the company, fulfilling also a major focus of generating qualification in tribology for flex engines. Management meetings in the company also leveraged more attention from development groups of the technological center of our company.

As the consortium did not have the product development goal, the project performance assessment becomes more subjective, mainly related to knowledge acquired, and how this knowledge can lead to gaining competitive advantage.

\section{Conclusions}

This article examined how the collaboration competitive environment can influence innovation. Research indicates the importance of collaboration in the innovation process; however, there is little evidence in the literature considering the competitive environment in the automotive sector. The consortium business ecosystem significantly affected the dynamics of collaboration, and hence the generation of innovation.

The results indicated that trust was more established by means of individual engagement developed throughout the consortium, and less by the contractual formalization of it. This trust ensured a better flow of knowledge, and even the generation of projects in partnership parallel to the consortium. Although it was a big challenge mainly for automakers, learning how to build a relationship of trust was one of the main benefits identified in the research.

Another major challenge was the difficulty in the management of all knowledge generated in the consortium six years. The results showed the need for a consortium like this to have a fully dedicated person in the operational part of organizing and disseminating the entire material produced. Moreover, it is essential to have a detailed analysis of what is produced and how this knowledge can and should be disclosed to the companies involved. To which extent the result as an argument, for example, can influence the working environment of a specific company? Not necessarily all that is produced has the same relevance to all stakeholders. The organization, detailed analysis and efficient disclosure are essential in this knowledge management process. On the other hand, it is essential that companies also develop skills internally to use acquired knowledge in a profitable way, whether to develop a process, a technology or even a final product.

Universities have an important role in the consortium. At the beginning not even companies knew which would be their main contributions or even how they could be benefited from academic knowledge. This question demanded hard work, and over time stakeholders began to realize that the major contribution of Universities would in fact be the qualification of people involved. Not a technical qualification, since professionals were already quite familiar with tribology, but a qualification to work knowledge in a structured manner, focusing on the objectives to be achieved. 
This study provides an important advance in three aspects. First, it brings outstanding contributions to the process of generation of ideas and knowledge in a context that involves collaboration and competition simultaneously. In addition, the research examines how this has evolved over time, which were the main difficulties, which were the most significant barriers and necessary efforts to mitigate them. Another important contribution was learning generated on how to work ideas and opportunities in the Fuzzy Front End phase of innovation. Finally, it contributes to the identification of the main roles of Universities in this context.

A limitation of this research is the choice of the single case study method. The results of this research serve as a starting point for further research on the subject such as conducting other case studies in different industrial sectors. A survey could also be conducted to quantify how much companies are really seeking to collaborate in a competitive environment in order to improve their results of innovation and gain competitive advantage. Another research limitation refers to the superficial analysis of implementation barriers, which could be exploited in future research.

The Brazilian reality in the automotive sector is quite different from other countries, starting with the increased use of ethanol as fuel. Future research could explore the main differences between countries and how these differences may influence the outcome of innovation. Do countries where automotive companies have been working collaboratively over time face the same difficulties those Brazilian companies have faced? How the differences in legislation can influence the goals of these companies, and hence which is the way to go to achieve them?

\section{References}

Abernathy, W. J., \& Clark, K. B. (1985). Innovation: mapping the winds of creative destruction. Research Policy, 14(1), 3-22. http:// dx.doi.org/10.1016/0048-7333(85)90021-6.

Amara, N., \& Landry, R. (2005). Sources of information as determinants of novelty of innovation in manufacturing firms: evidence from the 1999 Statistics Canada Innovation Survey. Technovation, 25(3), 245-259. http://dx.doi.org/10.1016/S0166-4972(03)00113-5.

Ariño, A. (2003). Measures of strategic alliance performance: an analysis of construct validity. Journal of International Business Studies, 34(1), 66-79. http://dx.doi.org/10.1057/palgrave.jibs.8400005.

Armellini, F., Kaminski, O. C., \& Beaudry, C. (2011). Consortium for research and innovation in aerospace in Quebec, Canada: a reference model for the Brazilian aerospace industry. Research Policy, 26, 191-207.

Bidault, F., \& Castello, A. (2009). Trust and creativity: understanding the role of trust in creativity oriented joint developments. $R \& D$ Management, 39(3), 259-270. http://dx.doi.org/10.1111/j.1467-9310.2009.00557.x.

Blomqvist, K., Hurmelinna, P., \& Seppänen, R. (2005). Playing the collaboration game right: balancing trust and contracting. Technovation, 25(5), 497-504. http://dx.doi.org/10.1016/j.technovation.2004.09.001.

Bogers, M. (2011). The open innovation paradox: knowledge sharing and protection in R\&D collaborations. European Journal of Innovation Management, 14(1), 93-117. http://dx.doi.org/10.1108/14601061111104715.

Brandenburger, A. M., \& Nalebuff, B. (1995). The right game: use game theory to shape strategy. Harvard Business Review, 73, 57-71.

Branstetter, L. G., \& Sakakibara, M. (2002). When do research consortia work well and why? Evidence from Japanese panel data. The American Economic Review, 92(1), 143-159. http://dx.doi.org/10.1257/000282802760015649.

Bruneel, J., D’Este, P., \& Salter, A. (2010). Investigating the factors that diminish the barriers to university-industry collaboration. Research Policy, 39(7), 858-868. http://dx.doi.org/10.1016/j.respol.2010.03.006.

Bstieler, L., Hemmert, M., \& Barczak, G. (2015). Trust formation in university-industry collaborations in the U.S. Biotechnology Industry: IP policies, shared governance, and champions. Journal of Product Innovation Management, 32(1), 111-121. http://dx.doi. org/10.1111/jpim.12242.

Buganza, T., \& Verganti, R. (2009). Benefícios da cooperação entre compradores e fornecedores: um estudo no setor de tecnologia de informação e comunicação. European Journal of Innovation Management, 12(3), 306-325. http://dx.doi.org/10.1108/14601060910974200.

Caloghirou, Y., Kastelli, l., \& Tsakanikas, A. (2004). Internal capabilities and external knowledge sources: complements or substitutes for innovative performance? Technovation, 24(1), 29-39. http://dx.doi.org/10.1016/S0166-4972(02)00051-2.

Cammarano, A., Caputo, M., Lamberti, E., \& Michelino, F. (2017). Open innovation and intellectual property: a knowledge-based approach. Management Decision, 55(6), 1182-1208. http://dx.doi.org/10.1108/MD-03-2016-0203.

Carvalho, M. M. (2009). Inovação: estratégias e comunidades de conhecimento. São Paulo: Atlas.

Chang, Y.-C. (2003). Benefits of co-operation on innovative performance: evidence from integrated circuits and biotechnology firms in the UK and Taiwan. $R \& D$ Management, 33(4), 425-437. http://dx.doi.org/10.1111/1467-9310.00308.

Cheng, C. C. J., \& Huizingh, E. K. R. E. (2014). When is open innovation beneficial? The role of Strategic orientation. Journal of Product Innovation Management, 31(6), 1235-1253. http://dx.doi.org/10.1111/jpim.12148.

Cheng, C. C. J., \& Shiu, E. C. (2015). The inconvenient truth of the relationship between open innovation activities and innovation performance. Management Decision, 53(3), 625-647. http://dx.doi.org/10.1108/MD-03-2014-0163.

Christensen, C. M. (1997). Making strategy: learning by doing. Harvard Business Review, 75(6), 141-146. PMid:10174795.

Cohen, W. M., \& Levinthal, D. A. (1990). Absorptive-capacity: a new perspective on learning and innovation. Administrative Science Quarterly, 35(1), 128-152. http://dx.doi.org/10.2307/2393553.

Corbin, J., \& Strauss, A. (1990). Grounded theory research: procedures, canons, and evaluative criteria. Qualitative Sociology, 13(1), 3-21. http://dx.doi.org/10.1007/BF00988593. 
Edwards, T. (2000). Innovation and organizational change: developments towards an interactive process perspective. Technology Analysis and Strategic Management, 12(4), 445-464. http://dx.doi.org/10.1080/713698496.

Eisenhardt, K. M., \& Graebner, M. E. (2007). Theory building from cases: opportunities and challenges. Academy of Management Journal, 50(1), 25-32. http://dx.doi.org/10.5465/amj.2007.24160888.

Erez, M., Lee, C., \& Zhong, W. (2016). Can cooperating with competitors benefit innovation? A cross-cultural study. International Journal of Psychology, 51, 750-751.

Faems, D., Van Looy, B., \& Debackere, K. (2005). Interorganizational collaboration and innovation: toward a portfolio approach. Journal of Product Innovation Management, 22(3), 238-250. http://dx.doi.org/10.1111/j.0737-6782.2005.00120.x.

Frishammar, J., Ericsson, K., \& Patel, P. C. (2015). The dark side of knowledge transfer: exploring knowledge leakage in joint R\&D projects. Technovation, 41-42, 75-88. http://dx.doi.org/10.1016/j.technovation.2015.01.001.

Garcia, R., \& Calantone, R. (2002). A critical look at technological innovation typology and innovativeness terminology: a literature review. Journal of Product Innovation Management, 19(2), 110-132. http://dx.doi.org/10.1016/S0737-6782(01)00132-1.

Gesing, J., Antons, D., Piening, E. P., Rese, M., \& Salge, T. D. (2015). Joining forces or going it alone? On the interplay among external collaboration partner types, interfirm governance modes, and internal R\&D. Journal of Product Innovation Management, 32(3), 424-440. http://dx.doi.org/10.1111/jpim.12227.

Ghisetti, C., Marzucchi, A., \& Montresor, S. (2015). The open eco-innovation mode: an empirical investigation of eleven European country. Research Policy, 44(5), 1080-1093. http://dx.doi.org/10.1016/j.respol.2014.12.001.

Gnyawali, D. R., \& Park, B.-J. R. (2009). Co-opetition and technological innovation in small and medium-sized enterprises: a multilevel conceptual model. Journal of Small Business Management, 47(3), 308-330. http://dx.doi.org/10.1111/j.1540-627X.2009.00273.x.

Gnyawali, D. R., \& Park, B.-J. R. (2011). Co-opetition between giants: collaboration with competitors for technological innovation. Research Policy, 4O(5), 650-663. http://dx.doi.org/10.1016/j.respol.2011.01.009.

Gnyawali, D. R., He, J., \& Madhavan, R. (2006). Impact of co-opetition on firm competitive behavior: an empirical examination. Journal of Management, 43(4), 507-530. http://dx.doi.org/10.1177/0149206305284550.

Greco, M., Grimaldi, M., \& Cricelli, L. (2017). Hitting the nail on the head: exploring the relationship between public subsidies and open innovation efficiency. Technological Forecasting and Social Change, 118, 213-215. http://dx.doi.org/10.1016/j.techfore.2017.02.022.

Gulati, R., \& Singh, H. (1998). The architecture of cooperation: managing coordination costs and appropriation concerns in strategic alliances. Administrative Science Quarterly, 43(4), 781-814. http://dx.doi.org/10.2307/2393616.

Gulati, R., Nohria, N., \& Zaheer, A. (2000). Strategic network. Strategic Management Journal, 2 1(3), 203-215. http://dx.doi.org/10.1002/ (SICI) 1097-0266(200003)21:3<203::AID-SMJ102>3.0.C0;2-K.

Harrigan, K. R., \& Newman, W. H. (1990). Bases of interorganization co-operation: propensity, power, persistence. Journal of Management Studies, 27(4), 417-434. http://dx.doi.org/10.1111/j.1467-6486.1990.tb00255.x.

Huang, M.-H., \& Chen, D.-Z. (2017). How can academic innovation performance in university-industry collaboration be improved? Technological Performance and Social Change, 123, 210-215. http://dx.doi.org/10.1016/j.techfore.2016.03.024.

Huston, L., \& Sakkab, N. (2007). Connect and develop: inside Procter \& Gamble’s new model for innovation. Harvard Business Review, 84(3), 58-66. PMid:17348170.

Ingham, M., \& Mothe, C. (1998). How to learn in R\&D partnerships? R\&D Management, 28(4), 249-261. http://dx.doi.org/10.1111/14679310.00102.

Jameson, J., Ferrell, G., Kelly, J., Walker, S., \& Ryan, M. (2006). Building trust and shared knowledge in communities of E-learning practice: collaborative leadership in the JISC eLISA and CAMEL lifelong learning projects. British Journal of Educational Technology, 376), 949-967. http://dx.doi.org/10.1111/j.1467-8535.2006.00669.x.

Jorde, T. M., \& Teece, D. J. (1989). Competition and cooperation: striking the right balance. California Management Review, 31(3), 25-37. http://dx.doi.org/10.2307/41166568.

Kafouros, M., Wang, C., Piperopoulos, P., \& Zhang, M. (2015). Academic collaborations and firm innovation performance in China: the role of region-specific institutions. Research Policy, 44(3), 803-817. http://dx.doi.org/10.1016/j.respol.2014.11.002.

Kessler, E. H., Bierly, P. E., \& Gopalakrishnan, S. (2000). Internal vs external learning in new product development: effects on speed, costs and competitive advantage. $R \& D$ Management, 30(3), 213-223. http://dx.doi.org/10.1111/1467-9310.00172.

Kim, J., \& Wilemon, D. (2002). Focusing the fuzzy front-end in new product development. R\&D Management, 32(4), 269-279. http:// dx.doi.org/10.1111/1467-9310.00259.

Kim, S., Kim, H., \& Kim, E. (2016). Knowledge flow affects Korean ICT manufacturing performance: a focus on open innovation strategy. Technology Analysis and Strategic Management, 28(10), 1167-1181. http://dx.doi.org/10.1080/09537325.2016.1182150.

Koen, P., Ajamian, G., Burkart, R., Clamen, A., Davidson, J., D’Amore, R., Elkins, C., Herald, K., Incorvia, M., Johnson, A., Karol, R., Seibert, R., Slavejkov, A., \& Wagner, K. (2001). Providing clarity and a common language to the "Fuzzy Front End". Research Technology Management, 44(2), 46-55. http://dx.doi.org/10.1080/08956308.2001.11671418.

Kogut, B. (1988). Joint ventures: theoretical and empirical perspectives. Strategic Management Journal, 9(4), 319-332. http://dx.doi. org/10.1002/smj.4250090403.

Lau, A. K., \& Lo, W. (2015). Regional innovation system, absorptive capacity and innovation performance: an empirical study. Technological Forecasting and Social Change, 92, 99-114. http://dx.doi.org/10.1016/j.techfore.2014.11.005.

Lin, C., Tsai, H.-L., \& Wu, J.-C. (2014). Collaboration strategy decision-making using the Miles and Snow typology. Journal of Business Research, 67(9), 1979-1990. http://dx.doi.org/10.1016/j.jbusres.2013.10.013.

Lin, J.-Y. (2017). Balancing industry collaboration and academic innovation: the contingent role of collaboration-specific attributes. Technological Forecasting and Social Change, 123, 216-228. http://dx.doi.org/10.1016/j.techfore.2016.03.016.

Locke, K. D. (2003). Grounded theory in management research. London: Sage Publications. http://dx.doi.org/10.4135/9780857024428.

Mangematin, V., \& Nesta, L. (1999). What kind of knowledge can a firm absorb? International Journal of Technology Management, 37(3-4), 149-172. http://dx.doi.org/10.1504/IJTM.1999.002771. 
Morrison, P. D., Roberts, J. H., \& Von Hippel, E. (2000). Determinants of user innovation and innovation sharing in a local market. Management Science, 46(12), 1513-1527. http://dx.doi.org/10.1287/mnsc.46.12.1513.12076.

Murphy, S. A., \& Kumar, V. (1997). The front end of new product development: a Canadian survey. R \& D Management, 27(1), 5-15. http://dx.doi.org/10.1111/1467-9310.00038.

Naqshbandi, M. M. (2016). Managerial ties and open innovation: examining the role of absorptive capacity. Management Decision, 54(9), 1-25. http://dx.doi.org/10.1108/MD-03-2016-0161.

Nieto, M. J., \& Santamaria, L. (2007). The importance of diverse collaborative networks for the novelty of product innovation. Technovation, 27(6-7), 367-377. http://dx.doi.org/10.1016/j.technovation.2006.10.001.

Nooteboom, B. (1994). Innovation and diffusion in small firms: theory and evidence. Small Business Economics, 6(5), 327-347. http:// dx.doi.org/10.1007/BF01065137.

Odagiri, H., Nakamura, Y., \& Shibuya, M. (1997). Research consortia as a vehicle for basic research: the case of a fifth generation computer project in Japan. Research Policy, 26(2), 191-207. http://dx.doi.org/10.1016/S0048-7333(97)00008-5.

Pavitt, K. (1984). Sectoral patterns of technical change: towards a taxonomy and a theory. Research Policy, 13(6), 343-373. http:// dx.doi.org/10.1016/0048-7333(84)90018-0.

Perkmann, M., \& Schildt, H. (2015). Open data partnership between firms and universities: the role of boundary organizations. Research Policy, 44(5), 1133-1143. http://dx.doi.org/10.1016/j.respol.2014.12.006.

Perkmann, M., \& Walsh, K. (2007). University-industry relationships and open innovation: towards a research agenda. International Journal of Management Reviews, 9(4), 259-280. http://dx.doi.org/10.1111/j.1468-2370.2007.00225.x.

Popa, S., Soto-Acosta, P., \& Martinez-Conesa, 1. (2017). Antecedents, moderators, and outcomes of innovation climate and open innovation: an empirical study in SMEs. Technological Forecasting and Social Change, 118, 134-142. http://dx.doi.org/10.1016/j. techfore.2017.02.014.

Quintana-García, C., \& Benavides-Velasco, C. A. (2004). Cooperation, competition, and innovative capability: a panel data of European dedicated biotechnology firms. Technovation, 24(12), 927-938. http://dx.doi.org/10.1016/S0166-4972(03)00060-9.

Ritala, P., Olander, H., Michailova, S., \& Husted, K. (2015). Knowledge sharing, knowledge leaking and relative innovation performance: an empirical study. Technovation, 35, 22-31. http://dx.doi.org/10.1016/j.technovation.2014.07.011.

Santoro, M. D., \& Saparito, P. A. (2003). The firm's trust in its University partner as a key mediator in advancing knowledge and new technologies. IEEE Transactions on Engineering Management, 50(3), 362-373. http://dx.doi.org/10.1109/TEM.2003.817287.

Schilling, M. A., \& Phelps, C. C. (2007). Inter firm collaboration networks: the impact of large-scale network structure innovation. Management Science, 53(7), 1113-1126. http://dx.doi.org/10.1287/mnsc.1060.0624.

Schumpeter, J. A. (1934). The theory of economic development. New Jersey: Transactions Publishers.

Sherwood, A. L., \& Covin, J. G. (2008). Knowledge acquisition in university-industry alliances: an empirical investigation from a learning theory perspective. Journal of Product Innovation Management, 25(2), 162-179. http://dx.doi.org/10.1111/j.1540-5885.2008.00292.x.

Shvindina, H. O. (2017). Innovation of strategic management development from competition to competition. Marketing and Management of Innovations, 1(1), 180-192. http://dx.doi.org/10.21272/mmi.2017.1-16.

Smith, P. G., \& Reinertsen, D. G. (1998). Developing products in half the time. New York: John Wiley \& Sons.

Strauss, A., \& Corbin, J. (1990). Basics of qualitative research: grounded theory procedures and techniques. California: Sage Publications.

Takey, S. M., \& Carvalho, M. M. (2016). Fuzzy front end of systemic innovations: a conceptual framework based on a systematic literature review. Technological Forecasting and Social Change, 111, 97-109. http://dx.doi.org/10.1016/j.techfore.2016.06.011.

Teece, D. J. (1986). Profiting from technological innovation: implications for integration, collaboration, licensing and public policy. Research Policy, 15(6), 285-305. http://dx.doi.org/10.1016/0048-7333(86)90027-2.

Teece, D. J., Pisano, G. P., \& Shuen, A. (1997). Dynamic capabilities and strategic management. Strategic Management Journal, 18(7), 509-533. http://dx.doi.org/10.1002/(SICl) 1097-0266(199708) 18:7<509::AlD-SMJ882>3.0.C0;2-Z.

Tether, B. S., \& Tajar, A. (2008). Beyond industry-university links: sourcing knowledge for innovation from consultants, private research organizations and the public science-base. Research Policy, 37(6-7), 1079-1095. http://dx.doi.org/10.1016/j.respol.2008.04.003.

Un, C. A., \& Asakawa, K. (2015). Types of R\&D collaborations and process innovation: the benefit of collaborating upstream in the knowledge chain. Journal of Product Innovation Management, 32(1), 138-153. http://dx.doi.org/10.1111/jpim.12229.

West, J., \& Bogers, M. (2014). Leveraging external sources of innovation: a review of research on open innovation. Journal of Product Innovation Management, 31(4), 814-831. http://dx.doi.org/10.1111/jpim.12125.

Zhao, L., Xiang, Y., \& Yi, Q. (2017). Fuzzy front end patent management and innovation performance mediating role of patent commercialization and moderating effect of technological lock-in. Management Decision, 55(6), 1143-1162. http://dx.doi.org/10.1108/ MD-03-2016-0127. 
Appendix A. Interview protocol.

1. Is there an open innovation area in the company? If not, what area is responsible for this consortium?

2. Does this consortium involve multiple business units of your company?

3. How are the main aspects related to the intellectual property in your company and in the consortium worked?

4. What kind of partners are involved in this consortium?

5. What is the strategic importance of each partner in this consortium?

6. How did the selection process of these partners take place? What are the main difficulties?

7. What are the main factors that motivated your company to work in collaboration?

8. What is the interaction of your company with the other members of the consortium?

9. How did the knowledge flow among the participants?

10. Has the number of partners and people per company been sufficient?

11. How does your company manage the knowledge generated in the consortium?

12. Do you have the necessary skills and abilities to absorb the knowledge generated in the consortium?

13. Did the technological similarity influence the flow of knowledge among the consortium participants?

14. Did the geographical proximity influence the flow of knowledge among the consortium participants?

15. Has trust between partners evolved over the consortium?

16. With regard to how you work, what kind of meetings do you have? Is there any kind of socialization (breakfast, happy hour)?

17. How did the consortium contract work? What are the main difficulties?

18. How is the consortium information disseminated?

19. 1s there a consortium leader?

20. How does the consortium's idea generation process take place?

21 . What is the relationship between engine technology and innovation?

22. How does your company measure innovation performance?

23. How does your company measure the performance of the consortium? 